\title{
THE INITIATION OF AN INSECT PEST SURVEY IN PORTO RICO*
}

\author{
By M. D. Leonard, Entomologist, Insular Experiment Station, Río Piedras, \\ Porto Rico.
}

\section{ABSTRACT}

A brief account of the initiation of periodic observations and reports on the more important and injurious insects in Porto Rico in cooperation with the Insect Pest Survey office of the United States Bureau of Entomology. Faunal studies, both past and present are referred to and methods of collecting and recording Survey data are described. The objects of an Insect Pest Survey and the benefits to be derived from such work, both local and international, are suggested.

\section{PREVIOUS FAUNAL STUDIES}

Basic to an Insect Pest Survey in the strict meaning of the term is a thoro knowledge of what insects occur in the State or Country under consideration. Dr. L. O. Howard once stated that "All entomology is economic entomology." Since this is fundamentally largely if not entirely true, before the injurious or non-injurious nature of all the various species present can be properly evaluated, it is first highly desirable to know just what species comprise the insect fauna and their distribution, both geographical and seasonal. All studies, therefore, that have contributed towards such an end help to lay a valuable foundation for a detailed Insect Pest Survey of the territory.

Much work of this nature has fortunately been done in Porto Rico. The early accounts of Porto Rican insects by Fray Iñigo Abbad in 1788 and Andrés Pedro Ledru in 1810 followed by the extensive collections and studies of Dr. Augustín Stahl published in 1882 and of Drs. Leopold Krug and Juan Gundlach (1887-1893) form the basis of our knowledge of the insects of the Island.

In 1903 a Federal Experiment Station was established at Mayagüez and from then until 1924 several well-known entomologists, notably W. V. Tower, C. W. Hooker and R. H. Van Zwaluwenburg did much to increase our knowledge of the insects of the Island. In 1914 Van Zwaluwenburg compiled a typewritten list of the all insects recorded in Porto Rico to date with a supplement the fol-

* This paper was read before the 3rd Annual Meeting of the Eastern Branch of the American Association of Economic Entomologists held in New York City, November 19-20, 1931. 
lowing year. The Sugar Producers' Association established an Experiment Station in 1910 at Río Piedras which was reorganized three years later as the present Insular Bxperiment Station. For the past twenty years in this Station a great deal of data on Porto Rican insects has been accumulated by a number of well-trained workers, especially Van Dine, T. H. Jones, C. H. Hood, Crossman, Smyth, G. B. Merrill, Cotton, Wolcott, Seín and Dozier. In 1924. Wolcott published his "Insectae Portoricensis" in which he listed all of the insects known to oceur in the Island with notes on their distribution and food-plants. In this a total of upwards of 2500 species are mentioned. It is a most useful piece of work.

In 1913 the New Yorls Academy of Science in cooperation with the Porto Rican government conceived a plan of making a complete Scientific Survey of Porto Rico and the Virgin Islands. For several years beginning in 1914 a large number of insects were collected by F. E. Lutz, H. H. Crampton, A. J. Nutchler, C. W. Leng, F. E. Watson, II. G. Barber, L. B. Woodruff and others for inclusion in the reports of the Survey later on. To date a report has been published on part of the moths by Forbes and a report on the Diptera by Curran and a supplement to each has appeared during 1931 . The preparation of the reports on most of the other major orders of insects is well along so that in the course of a few years we will have a good basic knowledge of the insect fauna of the Island.

\section{INITIA'MON OF A MORMAL INSECT PEST SURVEX}

All of the above, however, is still not sufficient. In Porto Rico as in all other places we need to know not only what insects constitute the fauna but also the feeding habits of each, its seasonal and geographic distribution and its relative abundance during different parts of the year. Such information can be obtained only by systematic, frequent and continued observations made over a considerable period of time.

The writer has been greatly interested in the Insect Pest Survey conducted under the very able direction of Mr. J. A. Hyslop in the U. S. Burean of Entomology ever since its inception in 1921 and for the first few years while stationed in New York State was an active collaborator in this work. Shortly after coming to Porto Rico in January 1930 he was appointed an Official Collaborator of the Survey and began to make observations with that end in view. For many years, in fact since 1911, insect records at the Insular Experiment Station had been kept on so-called accession cards, each of which 
contains the notes in connection with specimens placed in the collection. Each eard bears a serial number of that year corresponding with the same number on the pinned specimens in the collection. The disadvantage of this method of keeping records for the purpose of an Insect Pest Survey is that the accession cards are filed numerically and not by the names of the insects; also that unless notes are accompanied by actual specimens in the collection they really have no proper place in the file. This has made it difficult to determine what observations have been made on any given insect since the close of Wolcott's "List" in 1923 and further it is not neeessary or desirable to continue to place specimens of many common and wellknown insects in the collection each time an observation is made concerning them.

At the Cleveland meeting of the American Association of Economic Entomologists in December $1930 \mathrm{Mr}$. Hyslop presented a brief paper showing how any entomologist could institute a simple record system for keeping track of observations on the activities of injurious insects in his territory (See Jour. Econ. Ent. 24(2) : 463-465, 1931) and offered to supply to anyone desiring them the standard record blanks in use in his office in Washington. Such a set of blanks was therefore obtained and the systematic recording of all observations possible on injurious insects in Porto Rico was commenced early in 1931. The accession card catalog has been kept up at the Station but is now used only where specimens are preserved in connection with individual observations and even in all such eases. the notes are also entered on the regular Survey record blanks.

By this system the whole process of recording and filing observations after they are made is surprisingly simple. In this way nothing of value is lost and many new and interesting records have already been obtained. Such records as were accumulated during 1930 (mostly during the second half of the year) were transferred to the standard record blanks and included in the file. Altho the Survey work has been a minor project of the Division of Entomology at the Station and not a great deal of time has been given to it we have been able to record in a little more than a year well over 500 individual observations on nearly 150 species of more or less injurious insects, distributed in over 100 genera. A number of species have been watched from month to month in order to determine more accurately their peaks and low points of activity. This is only the start. Its scope is continually expanding as we work with it. 
METHODS OF OBTAINING DATA

The methods of obtaining data are possibly for the most part no more than the obvious ones but they may be worth while mentioning. The two members of the staff at the Station at Río Piedras and Dr. Wolcott at the Sub-Station at Isabela make observations during trips on the Island and also locally on crops grown at or near the two Stations. Conversation or correspondence with at least certain members of the Division of Agricultural Extension in various parts of the Island and with the Superintendents of the Department's Experimental Farms bring to light many interesting notes. General correspondence from farmers and home-owners has also turned up much of value. Beginning July 1, 1931 several Specialists were appointed at the Station to cover work with most of the different crops grown in the Island. These men will make many observations as time goes on in the course of their official travels and indeed have already supplied some very worth-while data. A fertile source of information has been the local office of the U. S. Plant Quarantine \& Control Administration whose staff have made many interceptions since 1925 of injurious insects in Porto Rico both in the field and from fruits and vegetables offered for shipment to the Mainland. Such material has all been determined, wherever necessary, by the Specialists in the U. S. National Museum. From July 1930 thru October 1931 these interceptions included over 300 individual records on about 75 species distributed in about 60 genera, most of which were more or less injurious to crops.

Mr. Hyslop has suggested that the object of an Insect Pest Survey is to collect accurate and detailed information on the occurrence, distribution, ecology, and relative abundance of insect pests throughout the territory involved and to study these data from month to month and year'to year with relation to the several factors that influence insect abundance. The results to be obtained from a sur. vey of this nature, undertaken for a series of years are manifold; we should be able to throw light on the reasons for the cyclic and sporadic appearance of insect pests, the gradual shift of regions of destructive abundance, the limiting barriers to normal dispersal and the directive influences that determine the paths of insect diffusion. This is the necessary foundation for any advance toward the possibility of entomological forecasting. 
THE BENEFITS OF INSECT PEST SURVEYS

To further expand this suggestion: An attempt is being made to complete a picture. This is a mosaic however and as the years go on each record supplies a tile which fits into its proper place to help make up the whole. If enuf records could be obtained in a sufficient number of places with varied conditions and taken over a sufficient period of time much light would undoubtedly be shed upon insect activities which would prove of increasing practical value as time went on.

Intensity maps could be gradually filled out which, if properly correlated with temperature, humidity and rainfall would go far to show the effect of these factors on insect abundance. Further: altho breeding is more or less continuous in many places thruout the Tropies, it is well-known that in Porto Rico and also certain other places some insects, at least, are more abundant during the summer months, while others are more numerous in the winter season. This is in spite of the fact that the average mean temperature in Porto Rico, for example, varies but little from month to month. Reliable and continued observations on certain selected insects would do much to explain this phenomenon. Such observations should of course be correlated with data on the seasonal abundance of favored food-plants and other pertinent factors.

A more immediate value of Survey work is possibly the building up of definite data on the infestation of certain crops, positive or negative, which at once becomes of considerable value when plant quarantine questions arise. This has been shown very clearly during the past two years in Porto Rico and in those cases where sufficient conclusive evidence was lacking we wished greatly that a systematic Insect Pest Survey as such, had been in progress for a much longer time.

The writer has supplied to the office of Insect Pest Survey in Washington, besides a monthly report on insect conditions in Porto Rico, a summary report for both the fiscal years of 1929-30 and 1930-31. The former was published in the Annual Report of the Division of Entomology of the Insular Experiment Station for that year (pp. 110-123, 1931) and the latter will be published in the Jour. Dept. Agrr. Porto Rico, 16 (2) for April, 1932. This could also be done in other places to the great mutual advantage of both the Country concerned and the United States. If periodic monthly or bi-monthly, or even semi-annual or annual reports could be prepared by a competent person in a number of foreign countries and a copy 
sent for file in the office of Insect Pest Survey in Washington in: exchange of the monthly bulletin of that office a great mass of most valuable data could be accumulated of benefit to all concerned.

Such periodic reports should be encouraged and the necessary cooperation obtained from the proper officials, especially to start with in those countries which export the greatest variety of fruits and vegetables and other crops to the United States. It is encouraging to note that for the first time since the start of the Federal Insect Pest Survey reports have been received and published during this past year in the Insect Pest Survey Bulletin from places outside the mainland of the United States. These include one or more each from Hawaii, Mexico, Cuba, Fronduras, Guatemala, Costa Rica, Haití, Dominican Republic, Antigua (B. W. I.) and China in addition to Porto Rico. I understand from Mr. Hyslop that cooperation is now being solicited in addition to the above, from Pert, British Guiana, the State of Minas Geraes in Brazil, as well as several of the British West Indies for Survey reports during the coming year.

Regular commercial travel by airplane between the mainland of the United States and the West Indies and Central and South America is growing so rapidly that it is sure to greatly increase trade in plants and plant products with the United States. This will obviously augment plant quarantine problems and increase the necessity for a more accurate knowledge of the insect pests of all the countries concerned. Well-organized Insect Pest Surveys will supply the necessary information. They will of course be of value insofar as they are conducted with consistency and thoroness but any and all information that is accumulated will be well worth the effort spent in obtaining and recording it. 